\title{
The role of reactive oxygen species in the electrochemical inactivation of microorganisms
}


2

\begin{tabular}{|c|c|c|c|}
\hline \multicolumn{2}{|c|}{ Conditions } & \multirow{2}{*}{$\begin{array}{c}\mathrm{O}_{3} \text { generation } \\
(\mathrm{mg} / \mathrm{l})\end{array}$} & \multirow{2}{*}{$\mathrm{k}_{\mathrm{obs}}^{*}\left(\mathrm{~s}^{-1}\right)$} \\
\hline $\mathrm{pH}$ & $\mathrm{T}\left({ }^{\circ} \mathrm{C}\right)$ & & \\
\hline 7.1 & 4 & 0.14 & $1.98 \times 10^{-5}$ \\
\hline 7.1 & 15 & 0.05 & $1.93 \times 10^{-5}$ \\
\hline 7.1 & 25 & ND & $1.97 \times 10^{-5}$ \\
\hline 7.1 & 35 & ND & $1.95 \times 10^{-5}$ \\
\hline 5.6 & 25 & ND & $2.57 \times 10^{-5}$ \\
\hline 8.2 & 25 & ND & $1.41 \times 10^{-5}$ \\
\hline
\end{tabular}

ND : Not detected 